\title{
ANALISIS TATA KELOLA TEKNOLOGI INFORMASI DI RSUD DR.H.ABDUL MOELOEK PROVINSI LAMPUNG MENGGUNAKAN KERANGKA KERJA COBIT
}

\author{
Eka Diyah Surani \\ 1611050011 \\ Fakultas Bisnis \& Komputer \\ Ekadiyah@mail.darmajaya.ac.id
}

\begin{abstract}
Penerapan sistem informasi di RSUD Kota Bandar Lampung bertujuan untuk mempermudah proses administrasi. Agar kinerja sistem informasi dapat berjalan sesuai dengan perencanaan, dan tujuan bisnis rumah sakit maka dibutuhkan pengukuran atau audit guna mengetahui kematangan kinerja sistem informasi tersebut agar dapat memberikan peranan teknologi informasi yang baik. Audit sistem informasi menggunakan Framework COBIT sangat berguna baik bagi pengguna dan auditor maupun bagi manajemen. Tujuan dari penelitian ini adalah untuk mengetahui tingkat kematangan Sistem Informasi di RSUD Kota Bandar Lampung. Tujuan lain dari penelitian ini adalah agar dapat memberikan rekomendasi yang dapat digunakan sebagai bahan perbaikan sistem informasi di masa yang akan datang. Hasil dari penelitian ini menunjukkan skor tingkat kematangan sistem informasi di RSUD Kota Bandar Lampung yang diperoleh yaitu 3 atau berada pada level Defined Process dari total 22 sudomain yang ditemukan hanya 6 menunjukkan skor tingkat kematangan level 2 (Repeatable but Intuitive) yang diberikan rekomendasi.
\end{abstract}

Kata kunci : Audit, Framework COBIT, Tingkat kematangan. 


\section{Tugas Besar Individu}

\section{A. KESIMPULAN SARAN}

1. Kesimpulan

Berdasarkan dari hasil analisis yang telah dilakukan maka dapat diambil beberapa kesimpulan yang berhubungan dengan sistem informasi di Rumah Sakit Umum Daerah B Dr.H.Abdul Moeloek yaitu

a. Berdasarkan hasil analisis data yang dilakukan menggunakan perhitungan maturity level dari framework COBIT. pada sistem informasi di RSUD Dr.H.Abdul Moeloek diperoleh rata - rata tingkat kematangan berada pada level 3, yaitu defined process yang berarti seluruh proses telah didokumentasikan dan telah dikomunikasikan, serta dilaksanakan berdasarkan metode pengembangan sistem komputerisasi yang baik, namun belum ada proses evaluasi terhadap sistem tersebut, sehingga masih ada kemungkinan terjadinya penyimpangan.

b. Pada sistem informasi di RSUD Dr.H.Abdul Moeloek terdapat 6 proses yang berada pada level repeatable but intuitive dan
16 proses pada level defined process. Hasil temuan dan nilai kedewasaan harus dipertahankan, sedangkan untuk proses - proses yang masih dibawah tingkat kedewasaan diharapkan maka harus lebih diperhatikan dan ditingkatkan lagi agar selaras dengan level yang sudah ada yaitu defined process.

c. Hasil analisis GAP (General Accounting Principle) atau kesenjangan tingkat kematangan pada keseluruhan proses yaitu sebesar 1. Hal ini berarti untuk mencapai nilai maturity level dari level 2 (repeatable but intuitive) sampai ke level 3 (defined process) yaitu dengan melakukan perbaikan seperti rekomendasi yang diberikan.

d. Menghasilkan rekomendasi audit sistem informasi pada domain yang memiliki tingkat kematangan level 2 atau repeatable but intuitive, dengan total rekomendasi sebanyak 6 rekomendasi.

2. Saran

a. Pada penelitian ini penulis hanya berfokus 
pada audit sistem

informasi,

diharapkan pada proses

penelitian selanjutnya

dilakukan dengan lingkup yang lebih luas yaitu audit tata kelola teknologi informasi.

b. Diharapkan pada proses penelitian selanjutnya dapat menggunakan model

audit selain COBIT 4.1, karena COBIT hanya berfokus pada kendali dan pengukuran. Selain itu COBIT hanya memberikan panduan kendali dan tidak memberikan panduan implementasi operasional.

\section{B. TINJAUAN PUSTAKA}

Menurut Mahmudi (2010), pengukuran kinerja merupakan suatu proses penilaian kemajuan pekerjaan terhadap pencapaian tujuan dan sasaran yang telah ditentukan, termasuk informasi atas efisiensi penggunaan sumber daya dalam menghasilkan barang atau jasa, perbandingan hasil kegiatan dengan target, dan efektivitas tindakan dalam mencapai tujuan. Pengukuran kinerja penting dilakukan karena merupakan alat untuk menilai kesuksesan organisasi. Kinerja organisasi adalah gambaran tingkat pencapaian pelaksanaan suatu kegiatan atau program atau kebijaksanaan dalam mewujudkan sasaran, tujuan, misi dan visi organisasi (Inpres no 7/99). Pengukuran kinerja juga merupakan salah satu elemen penting sistem pengendalian manajemen karena pengukuran kinerja dapat digunakan untuk melakukan pengendalian aktivitas (Widjono. Dj, 1999).

\section{METODE PENELITIAN}

Untuk menyelesaikan penelitian secara objektif, maka penulis menggunakan beberapa metode:

1. Metode Pengumpulan Data Pengumpulan data dilakukan untuk mendapatkan keterangan mengenai semua hal yang berhubungan dengan penelitian. Metode pengumpulan data yang digunakan dalam penelitian ini adalah:

a. Metode Observasi

Observasi dilakukan dengan tujuan untuk mengamati proses bisnis yang sedang berjalan di RSUD Dr.H.Abdul Moeloek guna mengumpulkan data yang diperlukan. 
b. Metode Wawancara Penulis melakukan secara langsung kepada pihak pihak di RSUD Dr.H.Abdul Moeloek yang terkait dengan topik penelitian. Adapun hal - hal yang ditanyakan pada sesi wawancara adalah yang berkaitan dengan pokok permasalahan yaitu seputar sistem informasi yang diterapkan di RSUD Dr.H.Abdul Moeloek.

c. Metode Kuesioner Peneliti membuat kuisioner berdasarkan pemetaan business goals sesuai dengan framework COBIT dan menyebarkan kepada responden yang terkait dengan kuisioner tersebut, yaitu admin dan karyawan yang menjalankan sistem informasi di RSUD Dr.H.Abdul Moeloek.

d. Studi Literatur Sebagai pelengkap dalam pengumpulan data selain kuesioner dan wawancara, penelitian menggunakan metode studi kepustakaan dengan membaca, mempelajari buku - buku dan jurnal sebagai pendukung dalam penulisan dan penyusunan penelitian ini.
Kerangka pikir penelitian yang digunakan dalam penelitian ini adalah berdasarkan:

a. kerangka kerja COBIT

b. Identifikasi Business Goals

c. Control Objectives

d. Identifikasi IT Process

e. Identifikasi IT Goals Perhitungan Tingkat Kematangan (Maturity Level) didapatkan dari keterkaitan antara proses teknologi informasi yang berjalan diinstansi dengan proses teknologi informasi berdasarkan kerangka kerja COBIT.

\section{Control Objectives Control Objectives}

merupakan bagian dari detail proses teknologi informasi, dimana tidak semua control objective akan dipakai dalam proses teknologi informasi. 5. Perhitungan Tingkat Kematangan (Maturity Level) Pada tahap ke lima dari penelitian ini

adalah perhitungan maturity level, sesuai dengan maturity model berdasarkan kerangka kerja COBIT.

2. Kerangka Pikir Penelitian 
1. Identifikasi Business Goals

Pada tahap ini akan dilakukan analisis tujuan bisnis dari RSUD Dr.H.Abdul Moeloek untuk memperoleh gambaran kemana arah yang akan dituju instansi tersebut, kemudian tujuan bisnis tersebut disesuaikan pandangannya yang sesuai dengan domain yang ada pada framework COBIT.

\section{Identifikasi IT Goals}

Pada tahap ini akan diidentifikasi tujuan dari pengembangan teknologi informasi berdasarkan tujuan bisnis instansi yang telah ditentukan sebelumnya. Pada tahap ini tujuan teknologi informasi akan didapatkan dengan cara menghubungkan antara tujuan bisnis dengan tujua teknologi informasi berdasarkan kerangka kerja COBIT.

\section{Identifikasi IT Process}

Pada tahap ini akan diidentifikasi proses teknologi informasi yang telah ditentukan sebelumnya. Pada tahap ini proses teknologi informasi akan

\section{HASIL DAN PEMBAHASAN}

\section{Identifikasi Proses \\ Teknologi Informasi}

Pada tahap ini, dilakukan penetapan proses teknologi informasi yang sesuai dengan standar COBIT. Penetapan proses tersebut didasarkan dari hasil studi pustaka dalam memperlajari COBIT dan literatur terkait serta hasil observasi yang diperoleh dari objek yang diteliti. Adapun susunan proses teknologi informasi di RSUD Dr.H.Abdul Moeloek menurut domain standar COBIT yang telah dipilih dijabarkan pada tabel 2 berikut:

\begin{tabular}{|c|c|}
\hline IT Domain & $\begin{array}{c}\text { IT } \\
\text { Proce } \\
\text { ss }\end{array}$ \\
\hline $\begin{array}{l}\text { Plan and } \\
\text { Organize }\end{array}$ & $\begin{array}{l}\text { PO2, } \\
\text { PO3, } \\
\text { PO4, } \\
\text { PO5, } \\
\text { PO6, } \\
\text { PO7, } \\
\text { PO8 }\end{array}$ \\
\hline $\begin{array}{l}\text { Acquire } \\
\text { and } \\
\text { Implement } \\
\text { ation }\end{array}$ & $\begin{array}{l}\mathrm{AI} 2, \\
\mathrm{AI} 3, \\
\mathrm{AI} 4 \\
\mathrm{AI} 5 \\
\mathrm{AI} 6 \\
\mathrm{AI} 7\end{array}$ \\
\hline $\begin{array}{l}\text { Deliver and } \\
\text { Support }\end{array}$ & $\begin{array}{l}\text { DS1, } \\
\text { DS2, } \\
\text { DS4, }\end{array}$ \\
\hline
\end{tabular}




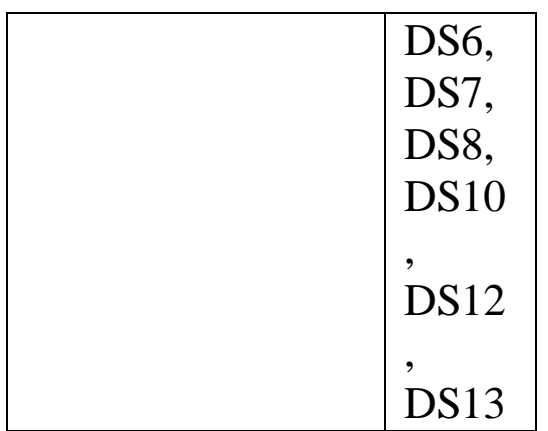

2. Pengukuran Tingkat Kematangan Sistem Informasi di RSUD Dr.H.Abdul Moeloek

Berdasarkan hasil survey dengan alat kuesioner COBIT pada domain PO, AI dan DS diperoleh hasil penggambaran dari penerapan sistem informasi di RSUD Dr.H.Abdul Moeloek. Hasil penggambaran ini diperoleh dengan cara melakukan perhitungan tingkat kematangan terhadap penerapan sistem informasi berdasarkan hasil survey dengan alat kuesioner COBIT. Adapun hasilnya dalam tabel sebagai berikut :

\begin{tabular}{|c|l|c|c|c|c|}
\hline \multirow{2}{*}{ No } & \multirow{2}{*}{ Proses } & \multicolumn{2}{|c|}{ Maturity Level } & \multirow{2}{*}{ Rata - rata } & \multirow{2}{*}{ Pembulatan } \\
\cline { 3 - 4 } & & Responden 1 & Responden 2 & & \\
\hline 1 & PO2 & 2.66 & 2.66 & 2.66 & 3 \\
\hline 2 & P03 & 2.47 & 2.47 & 2.47 & 2 \\
\hline 3 & P04 & 2.8 & 2.8 & 2.8 & 3 \\
\hline 4 & P05 & 2.6 & 2.6 & 2.6 & 3 \\
\hline 5 & P06 & 2.3 & 2.3 & 2.3 & 2 \\
\hline 6 & P07 & 2.31 & 2.31 & 2.31 & 2 \\
\hline 7 & P08 & 2.66 & 2.66 & 2.66 & 3 \\
\hline 8 & AI2 & 2.88 & 2.88 & 2.88 & 3 \\
\hline 9 & AI3 & 2.61 & 2.61 & 2.61 & 3 \\
\hline 10 & AI4 & 2.51 & 2.51 & 2.51 & 3 \\
\hline 11 & AI5 & 2.44 & 2.44 & 2.44 & 2 \\
\hline 12 & AI6 & 2.44 & 2.44 & 2.44 & 2 \\
\hline 13 & AI7 & 2.51 & 2.51 & 2.51 & 3 \\
\hline 14 & DS1 & 2.52 & 2.52 & 2.52 & 3 \\
\hline 15 & DS2 & 2.6 & 2.6 & 2.6 & 3 \\
\hline 16 & DS4 & 2.56 & 2.56 & 2.56 & 3 \\
\hline 17 & DS6 & 2.51 & 2.51 & 2.51 & 3 \\
\hline 18 & DS7 & 2.55 & 2.55 & 2.55 & 3 \\
\hline 19 & DS8 & 2.72 & 2.72 & 2.72 & 3 \\
\hline 20 & DS10 & 2.51 & 2.51 & 2.51 & 3 \\
\hline 21 & DS12 & 2.72 & 2.72 & 2.72 & 3 \\
\hline 22 & DS13 & 2.49 & 2.49 & 2.49 & 2 \\
\hline & & Rata - rata & & 2.56 & 3 \\
\hline
\end{tabular}

Hasil perhitungan mendapati rata - rata tingkat kematangan sistem informasi di RSUD Dr.H.Abdul Moeloek yaitu sebesar 3 . Dari nilai tersebut dapat ditarik kesimpulan bahwa penerapan sistem informasi berada pada level Defined Process, yang berarti bahwa pada RSUD Dr.H.Abdul Moeloek seluruh proses telah didokumentasikan dan telah dikomunikasikan, serta dilaksanakan berdasarkan metode pengembangan sistem komputerisasi yang baik, namun belum ada proses evaluasi terhadap sistem tersebut, sehingga 
masih ada kemungkinan terjadinya penyimpangan.

3. Nilai Kesenjangan

Kematangan Saat Ini

Setelah menilai dan mengetahui tingkat kematangan sistem informasi saat ini sebesar 3 maka dilakukan analisis kesenjangan terhadap tingkat kematangan yang diharapkan. Analisa ini diharapkan dapat memberikan kemudahan bagi pengelola teknologi informasi yang serasi. Berikut ini merupakan hasil perbandingan kesenjangan antara tingkat kematangan saat ini dengan tingkat kematangan diharapkan.

Perbandingan Kesenjangan antara Tingkat Kematangan Saat Ini dengan yang diharapkan:

\begin{tabular}{|c|c|c|c|}
\hline \multirow[b]{2}{*}{ Subdomain } & \multicolumn{3}{|c|}{ Tingkat Kematangan } \\
\hline & $\begin{array}{c}\text { Kematangan saat } \\
\text { ini (as - is })\end{array}$ & $\begin{array}{c}\text { Kematangan } \\
\text { Diharapkan (to - } \\
\text { be) }\end{array}$ & $\begin{array}{l}\text { GAP (Kematangan Diharapkan } \\
\text { - Kematangan Saat ini) }\end{array}$ \\
\hline $\mathrm{PO2}$ & 3 & 4 & $4-3=1$ \\
\hline $\mathrm{P} 03$ & 2 & 3 & $3-2=1$ \\
\hline $\mathrm{P} 04$ & 3 & 4 & $4-3=1$ \\
\hline P05 & 3 & 4 & $4-3=1$ \\
\hline P06 & 2 & 3 & $3-2=1$ \\
\hline $\mathrm{P} 07$ & 2 & 3 & $3-2=1$ \\
\hline P08 & 3 & 4 & $4-3=1$ \\
\hline $\mathrm{AI} 2$ & 3 & 4 & $4-3=1$ \\
\hline $\mathrm{Al}^{3}$ & 3 & 4 & $4-3=1$ \\
\hline AI4 & 3 & 4 & $4-3=1$ \\
\hline AI5 & 2 & 3 & $3-2=1$ \\
\hline Al6 & 2 & 3 & $3-2=1$ \\
\hline AI7 & 3 & 4 & $4-3=1$ \\
\hline DS1 & 3 & 4 & $4-3=1$ \\
\hline DS2 & 3 & 4 & $4-3=1$ \\
\hline DS4 & 3 & 4 & $4-3=1$ \\
\hline DS6 & 3 & 4 & $4-3=1$ \\
\hline DS7 & 3 & 4 & $4-3=1$ \\
\hline DSS & 3 & 4 & $4-3=1$ \\
\hline
\end{tabular}

Perbandingan Kesenjangan antara Tingkat Kematangan Saat Ini dengan yang diharapkan (Lanjutan):

\begin{tabular}{|c|c|c|c|}
\hline \multirow{2}{*}{$\begin{array}{l}\text { Subdomai } \\
\text { n }\end{array}$} & \multicolumn{3}{|c|}{ Tingkat Kematangan } \\
\cline { 2 - 4 } & $\begin{array}{c}\text { Kematanga } \\
\text { n saat ini } \\
\text { (as - is) }\end{array}$ & $\begin{array}{c}\text { Kematangan } \\
\text { Diharapkan (to - } \\
\text { be) }\end{array}$ & $\begin{array}{c}\text { GAP (Kematangan } \\
\text { Diharapkan - Kematangan } \\
\text { Saat ini) }\end{array}$ \\
\hline DS10 & 3 & 4 & $4-3=1$ \\
\hline DS12 & 3 & 4 & $4-3=1$ \\
\hline DS13 & 2 & 3 & $3-2=1$ \\
\hline \multicolumn{4}{|c|}{ Rata-rata } \\
\hline
\end{tabular}

1. Rekomendasi Untuk Meningkatkan Nilai 
Tingkat Rekomendasi untuk domain PO6

a. Perlu adanya pengendalian informasi dan lingkungan manajemen mutu yang lengkap dikembangkan, didokumentasikan dan dikomunikasikan oleh manajemen dan mencakup kerangka kerja untuk kebijakan, rencana dan prosedur.

b. Proses pengembangan kebijakan terstruktur, dipelihara dan diketahui oleh staf, dan kebijakan rencana dan prosedur yang ada cukup masuk akal dan mencakup isu isu kunci.

c. Perlu adanya pemantauan kepatuhan terhadap kebijakan dan prosedur secara konsisten mengenai kerangka pengembangan

keseluruhan untuk kebijakan dan prosedur pengendalian.

2. Rekomendasi untuk domain $\mathrm{PO} 7$

a. Harus ada proses yang didefinisikan dan terdokumentasi untuk mengelola sumber daya manusia bidang TI. b. Harus ada rencana pengelolaan sumber daya manusia bidang TI.

c. Perlu adanya rencana pelatihan formal dirancang untuk memenuhi kebutuhan sumber daya manusia bidang TI.

3. Rekomendasi untuk domain AI5

a. Manajemen melembagakan kebijakan dan prosedur untuk akuisisi TI.

b. Pemasok sumber daya TI diintegrasikan ke dalam mekanisme manajemen proyek organisasi dari perspektif manajemen kontrak.

c. Manajemen mengkomunikasik an kebutuhan akan akuisisi dan pengelolaan kontrak yang sesuai di seluruh fungsi TI.

4. Rekomendasi untuk domain AI6 
a. Perlu adanya proses manajemen perubahan formal yang ditetapkan, termasuk kategorisasi, prioritisasi, prosedur darurat, perubahan otorisasi dan manajemen pelepasan.

4. Kematangan sesuai dengan Harapan.

Ke enam domain dengan kondisi tingkat kematangan pada level 2 (Repeatable but Intuitive) yaitu PO3, PO6, PO7, AI5, AI6 dan DS13 mendapat prioritas utama untuk dilakukan perbaikan. Sehingga akan seimbang dengan tingkat kematangan rata - rata keselurhan domain yaitu tingkat kematangan yang berada pada level 3 (Defined). Untuk meningkatkan kondisi kesenjangan tingkat kematangan sistem informasi saat ini (as - is) dengan kondisi yang diharapkan (to be) pada ke enam domain yang memiliki tingkat kematangan level 2 (Repeatable but Intuitive) ke level 3 (Defined) maka penulis memberikan rekomendasi sebagai berikut

5. Rekomendasi untuk PO3 a. Manajemen perlu menyadari pentingnya rencana infrastruktur teknologi.

b. Perlunya proses pengembangan rencana infrastruktur teknologi cukup masuk akal dan selaras dengan rencana strategis TI.

c. Perlu adanya arah infrastruktur teknologi mencakup pemahaman tentang kemana organisasi ingin memimpin atau tertinggal dalam penggunaan teknologi, berdasarkan risiko dan keselarasan dengan strategi organisasi. b. Analisis dampak perubahan TI terhadap operasi bisnis mulai diformalkan, untuk mendukung peluncuran aplikasi dan teknologi baru yang direncanakan.

6. Rekomendasi untuk domain DS13

a. Kebutuhan akan
manajemen operasi
komputer perlu dipahami
dan diterima dalam
organisasi.




\author{
b. Kebijakan formal \\ dikembangkan untuk \\ mengurangi jumlah \\ kejadian tak terjadwal.
}

\section{REFERENCE}

[1] O. M. Febriani and A. S. Putra, "Sistem Informasi Monitoring Inventori Barang Pada Balai Riset Standardisasi Industri Bandar Lampung," J. Inform., vol. 13, no. 1, pp. 90-98, 2014.

[2] A. S. Putra, "Paperplain: Execution Fundamental Create Application With Borland Delphi 7.0 University Of Mitra Indonesia," 2018.

[3] A. S. Putra, "2018 Artikel Struktur Data, Audit Dan Jaringan Komputer," 2018.

[4] A. S. Putra, "ALIAS MANAGER USED IN DATABASE DESKTOP STUDI CASE DB DEMOS."

A. S. Putra, "COMPREHENSIVE SET OF PROFESSIONAL FOR DISTRIBUTE COMPUTING."

[6] A. S. Putra, "DATA ORIENTED RECOGNITION IN BORLAND DELPHI 7.0.”

[7] A. S. Putra, "EMBARCADERO DELPHI XE 2 IN GPUPOWERED FIREMONKEY APPLICATION."

[8] A. S. Putra, "HAK ATAS KEKAYAAN INTELEKTUAL DALAM DUNIA TEKNOLOGY BERBASIS REVOLUSI INDUSTRI 4.0."

[9] A. S. Putra, "IMPLEMENTASI
PERATURAN

PERUNDANGAN UU. NO 31

TAHUN 2000 TENTANG

DESAIN INDUSTRI

BERBASIS INFORMATION TECHNOLOGY."

[10]

A. S. Putra,

"IMPLEMENTATION OF PARADOX DBASE."

[11] A. S. Putra, "IMPLEMENTATION OF TRADE SECRET CASE STUDY SAMSUNG MOBILE PHONE."

[12] A. S. Putra, "IMPLEMENTATION PATENT FOR APPLICATION WEB BASED CASE STUDI WWW. PUBLIKLAMPUNG. COM."

[13] A. S. Putra, "IMPLEMENTATION SYSTEM FIRST TO INVENT IN DIGITALLY INDUSTRY."

[14] A. S. Putra, "MANUAL REPORT \& INTEGRATED DEVELOPMENT

ENVIRONMENT BORLAND DELPHI 7.0."

[15] A. S. Putra, "PATENT AS RELEVAN SUPPORT RESEARCH."

[16] A. S. Putra, "PATENT FOR RESEARCH STUDY CASE OF APPLE. Inc."

[17] A. S. Putra, "PATENT PROTECTION FOR APPLICATION INVENT."

[18] A. S. Putra, "QUICK REPORT IN PROPERTY PROGRAMMING."

[19] A. S. Putra, "REVIEW CIRCUIT LAYOUT COMPONENT REQUIREMENT ON ASUS 
[20] A. S. Putra, "REVIEW TRADEMARK PATENT FOR INDUSTRIAL TECHNOLOGY BASED 4.0."

[21]A. S. Putra, "TOOLBAR COMPONENT PALLETTE IN OBJECT ORIENTED PROGRAMMING."

[22] A. S. Putra, "WORKING DIRECTORY SET FOR PARADOX 7."

[23] A. S. Putra, "ZQUERY CONNECTION IMPLEMENTED PROGRAMMING STUDI CASE PT. BANK BCA Tbk."

[24] A. S. Putra, D. R. Aryanti, and I. Hartati, "Metode SAW (Simple Additive Weighting) sebagai Sistem Pendukung Keputusan Guru Berprestasi (Studi Kasus: SMK Global Surya)," in Prosiding Seminar Nasional Darmajaya, 2018, vol. 1, no. 1, pp. 85-97.

[25] A. S. Putra and O. M. Febriani, "Knowledge Management Online Application in PDAM Lampung Province," in Prosiding International conference on Information Technology and Business (ICITB), 2018, pp. 181-187.

[26] A. S. Putra, O. M. Febriani, and B. Bachry, "Implementasi Genetic Fuzzy System Untuk Mengidentifikasi Hasil Curian Kendaraan Bermotor Di Polda Lampung," SIMADA (Jurnal Sist. Inf. dan Manaj. Basis Data), vol. 1, no. 1, pp. 21-30, 2018.

[27] A. S. Putra, H. Sukri, and K. Zuhri, "Sistem Monitoring
Realtime Jaringan Irigasi Desa (JIDES) Dengan Konsep Jaringan Sensor Nirkabel," IJEIS (Indonesian J. Electron. Instrum. Syst., vol. 8, no. 2, pp. 221-232.

[28] D. P. Sari, O. M. Febriani, and A. S. Putra, "Perancangan Sistem Informasi SDM Berprestasi pada SD Global Surya," in Prosiding Seminar Nasional Darmajaya, 2018, vol. 1, no. 1, pp. 289-294. 